\author{
Tanses GULSOY \\ Olkan BUDAK \\ Beykent University, Turkey
}

\begin{abstract}
In the pharmaceuticals industry the relationship of the pharmaceutical sales representative to the physician is an important strategic resource for the firm. This study examines this relationship from the perspective of physicians in Turkey. A survey with 429 physicians from across Turkey underlined once again the importance of this business-to-business relationship. Preliminary findings indicate a strong positive relationship between physicians' satisfaction with the salesperson and intention to continue working with the pharmaceutical firm. Furthermore, significant differences are indicated between loyalty ratings of multinational and local pharmaceutical firms, with important implications for both local and multinational firms in the emerging-market context.
\end{abstract}

Keywords: relationship marketing; business-to-business marketing; pharmaceutical industry; pharmaceutical sales representatives, medical sales representatives.

\title{
INTRODUCTION
}

Buyer-seller relationships are very important in business-to-business marketing, and the relationship of the pharmaceutical sales representative to the physician emblematizes many aspects of the dyadic salesperson-customer relationship. The relationship marketing perspective has long maintained that the company's relationships with its customers are an important strategic resource (e.g., Parvatiyar and Sheth, 2000; Morgan, 2000; Buttle, 1996; Dwyer, Schurr, and Oh, 1987). A meta-analysis has revealed that relationship marketing positively affects performance and that relationship investment has a large, direct effect on seller objective performance (Palmatier, Dant, Grewal, and Evans, 2006). Long-term, mutually beneficial relationships in business-to-business markets have been found to yield may benefits such as anticipation of future interaction (e.g., Crosby, Evans, and Cowles, 1990), increased share of purchase, repurchase intentions, intention to expand business with the supplier, and willingness to recommend the seller among others, as documented by a literature review (Athanasopoulou, 2009). Therefore, managing this strategic resource effectively can enhance the company's competitiveness in its industry, improve its profitability, and contribute to its sustainable development.

Many studies point to the strategic role of the salesperson in business-to-business relationships. Research indicates that customer satisfaction with the salesperson may be critical in maintaining that customer's business. As the primary link between the buying and selling firms, salespeople may influence the buyer's perceptions regarding the seller's reliability, the value of the seller's services, and ultimately the buyer's commitment to the relationship (Biong and Slenes, 1996, as cited in Wright and Lundstrom, 2004).

In the pharmaceutical industry direct promotion targeting the physician is a common practice (Fickweiler, Fickweiler, and Urbach, 2017; Williams and Hensel, 1991). The pharmaceutical industry is one of the world's leading investors in research and development. In 2016, the pharmaceutical industry spent some 157 billion U.S. dollars on research and development (Statista, 2018a). Thus, it follows that the industry is in ever-growing need of marketing its innovative new products. As generic drug manufacturers challenge drug patents more vigorously, brandname manufacturers try to expand the boundaries of patent protection and shield their most successful drugs from generic competition (Cheng, 2008). Therefore, perhaps today more than ever the physician's satisfaction and loyalty are very important to 
Journal of Global Strategic Management | V. 12 | N. 2 | 2018-December| isma.info | 037-052 | DOI: 10.20460/JGSM.2019.267 pharmaceutical companies. Research indicates that provided adequate product quality, the main factors influencing competition in this market are the levels of service quality and the service performance of the sales representative (Scharitzer and Kollarits, 2000).

Since in most country-markets the multinational predominance in the pharmaceutical industry is prevalent and the world's pharmaceutical industry is dominated by companies originating from the US or Europe, where Johnson and Johnson, Roche, Pfizer, Novartis, and Bayer are the top five companies in terms of net sales for 2017 (Statista, 2018b), the perceived differences between the pharmaceutical sales representatives from local and multinational firms are of interest not only to pharmaceutical companies but to all companies where business-to-business relationships are of key concern. This is especially important in the emerging-market context where institutional rules and cultural norms may be different from the home countries of multinationals, the largest of which are mostly of developed countries. Emerging markets offer some unique challenges of their own (e.g., Khanna and Palepu, 1997).

Pharmaceutical companies use detailing, sampling, and sometimes direct-to-consumer advertising; in some emerging markets, however, consumer advertising of prescription as well as over-the-counter drugs may be banned, leaving physician-targeted approaches as the only alternative (Manchanda, Xie, and Youn, 2008). Governments in emerging markets sometimes do not include the products of multinationals in their reimbursement policy and pharmaceutical companies find it necessary to negotiate with reimbursement stakeholders (as pointed out by Gorokhovich, Chalkidou, and Shankar, 2013), which necessitates even greater reliance on physician-targeted communications.

As foreign and domestic pharmaceutical companies face different constraints in emerging markets, they may employ different relationship strategies with physicians. As a result, the consequences of those relationships - in the form of satisfaction with the salesperson or with the company and loyalty to the company - may differ between foreign and local companies as has been demonstrated in other productmarkets (e.g., Dong, Li and Tse, 2013).

The aim of the present study is twofold: to test the link between physician's salesperson satisfaction and prescription behavior and to explore whether the pharmaceutical sales representative's relationship to the physician customer differs according to the status of the pharmaceutical company, with its concomitant implications for the emerging-market context. Both lines of inquiry may yield fruitful insights into effective management of this business relationship. To the best of our knowledge, very few studies of the physician-pharmaceutical sales representative exist in the emerging-market context, as revealed by a literature review (Fickweiler, Fickweiler, and Urbach, 2017). In the Turkish context we have been able to locate very few studies focusing on this particular topic (e.g., Tengilimoglu, Kisa, and Ekiyor, 2004; Civaner, 2012). Consequently, a further aim of this study is to redress a research gap with our study.

\section{The Turkish context}

With a population of nearly 80 million people (World Bank, 2018), Turkey is the world's $16^{\text {th }}$ largest economy. Between 2015 and 2020 pharmaceutical sales growth is estimated to be higher in emerging countries than in developed countries with Brazil, Russia, India, China, Mexico, and Turkey ranking first with a 9.3\% growth in sales (Booz and Company, 2013, as cited in Tannoury and Attieh, 2017).

The pharmaceuticals market in Turkey is dominated by ten key players. Of these, eight are multinationals (Burton, 2018). The leading firm is a long-established local firm (Abdi Ibrahim, established in 1912) with a $5.80 \%$ market share, followed by Novartis (4.90\%), and Pfizer (4.2\%). Next come Sanofi (4.1\%), Bayer (3.9\%), Roche (3.6\%), and another longstanding local firm (Bilim İlaç, established in 1961) with a $2.9 \%$ market share. The remainder of these top firms are Merck Sharp \& Dohme, Glaxo Smith Kline, and East Pharma, each with a $2.7 \%$ market share. These ten firms account for $37.5 \%$ of the entire Turkish pharmaceuticals market, according to the most recent report by Pharmaboardroom, based on data received from Turkey's Association of Research-Based Pharmaceutical Companies (AIFD).

The multinationals in this group are also longstanding firms in the Turkish market. Three of them have been in the country since the 1950s, with Bayer taking the lead in 1954, followed by Pfizer (1957), and Roche (1958). Merck Sharp \& Dohme entered the market in 1992. It was followed by Novartis, which was formed following the merger of Ciba and Sandoz in 1996, Glaxo Smith Kline was formed following the merger of Glaxo Wellcome and Smith Kline Beecham in 2004, and Sanofi and Aventis, both of which had entered the market in 1999, merged in 2004 to establish Sanofi Aventis, which was later renamed 
Journal of Global Strategic Management | V. 12 | N. 2 | 2018-December| isma.info | 037-052 | DOI: 10.20460/JGSM.2019.267 Sanofi. On this list, the most recent arrival is EastPharma, which entered the market in 2006 by acquiring majority ownership of a long-established local firm Deva (1958).

A total of 492 pharmaceutical firms operate in Turkey, and of these 120 are foreign-equity firms, which account for around $66 \%$ of the market as of 2017, according to a 2018 report by the Pharmaceutical Manufacturers Association of Turkey (IEIS). Another characteristic of the market is that prescription drug advertising is banned (by a 1928 law, numbering 1262); therefore, physician-targeted detailing is one of the primary methods used by pharmaceutical companies, suggesting that the relationship between the pharmaceutical sales representative and the physician is very important.

The relationship between the physician and the pharmaceutical sales representative is governed by both a law dating from 1926 (No. 1262) and a decree (dated 2015, No. 29405) which is concerned with the rules of promoting health care products, in addition to standard operating procedures of pharmaceutical companies.

Our study was conducted against this institutional background. The remainder of this paper is structured as follows: Next is the literature review and theoretical framework, to be followed by research methodology. We then present our findings. The last section includes our conclusions, discussion of the limitations of our study, and managerial and research implications.

\section{LITERATURE REVIEW AND THEORETICAL FRAMEWORK}

Buyer-seller relationships are studied from various perspectives. The perspective adopted in this paper is that of the resource-based view of the firm and relationship marketing. The resource-based view treats the company's human resources and its relationships with key stakeholders as strategic assets. Regarded from that perspective, the boundary-spanning salesperson is an important resource for the firm (e.g., Crosby, Evans, and Cowles, 1990). Both the relationships formed with key customers and boundary spanners may constitute competitive advantages for the company.

Relationship marketing is an approach based on forming close, long-standing relationships with the company's key customers. Central to this perspective is the assumption that customers' attitudes to different suppliers is not just a function of product performance or the customer's evaluation of the competence of the supplier. A crucial aspect of competitiveness is the pattern and characteristics of the interaction with those suppliers, as noted by Turnbull, Ford, and Cunningham (2002: 13). Unless that relationship is well-managed, the benefits purported to issue from that relationship may not be realized (Ford, 1984). Consequently, relationship quality itself is part of customer-perceived quality, as noted by Gummesson (2002).

Important to this relationship is the boundary-spanning personnel such as the seller's salespeople and the buyer's purchasing center. Research has pointed to the key function performed by boundary spanners in the generation of future sales opportunities (e.g., Crosby, Evans, and Cowles, 1990), conflict resolution and cooperation (e.g., Huang, Luo, Liu, and Yang, 2013), and the role they may play in the formation, maintenance or dissolution of relationships (e.g., Seabright, Levinthal, and Fichman, 1992; Broschak, 2004).

Personal selling is one of the most effective means of marketing communication (e.g., Spiro and Weitz, 1990, as cited in Roman and Iacobucci, 2010), and the salesperson has a critical role to play, as noted by Kotler and Keller (2016: 664). Research indicates that a customer's loyalty to the salesperson appears to increase overall loyalty to the selling firm (Macintosh and Lockshin, 1997, as cited in Palmatier, Scheer, and Steenkamp, 2007; Palmatier et al., 2007) and positively affects selling-firm financial outcomes (Palmatier et al., 2007).

\section{The physician-pharmaceutical sales representative relationship}

The relationship between the physician and the pharmaceutical sales representative is an important business-to-business relationship. Research has indicated that physicians rely on information obtained during detailing visits from pharmaceutical sales representatives more than any other source when deciding whether to prescribe drugs (Van de Bulte and Lilien, 2001, as cited in Hewett and Krasnikov, 2016). Especially multinational pharmaceutical companies promote products in international markets mainly through developing relationships and exchange of information between sales representatives and physicians (Hewett and Krasnikov, 2016). 
Journal of Global Strategic Management | V. 12 | N. 2 | 2018-December| isma.info | 037-052 | DOI: 10.20460/JGSM.2019.267 The literature on the relationship between the physician and the pharmaceutical company's sales representatives indicates that the quality of this relationship is contingent upon several factors. For example, the relationship quality is more strongly related to physician purchase behavior when product complexity is high, but weaker when cultural distance is high and when authoritative mechanisms exist (Hewett and Krasnikov, 2016). Professional values of pharmaceutical sales representatives appear to significantly impact physician prescription loyalty (Waheed, Jaleel, and Laeequddin, 2011).

\section{The Model of the Study and Hypotheses}

We have based our study partly on the Doney and Cannon (1997) model which focuses on the antecedents and consequences of trust of a supplier firm and salesperson. The antecedents in the model are characteristics of the supplier firm, characteristics of the relationship with the supplier firm, characteristics of the salesperson, and characteristics of the salesperson relationship. These affect the buyer's trust of the supplier firm and the buyer's trust of the salesperson. Considering the special character of the relationship between the physician and the pharmaceutical sales representative, we have chosen the physician's satisfaction with the salesperson and the physician's loyalty as operationalized by his or her intention to continue his or her prescription behavior in lieu of the dependent variables used by Doney and Cannon (1997). Other consequences of this relationship may be recommendations of the pharmaceutical company's products, receptivity, and or denial/refusal (Wright and Lundstrom, 2004). For this preliminary study, we have simply considered the variables of physician's satisfaction with the pharmaceutical sales representative and physician's loyalty to the pharmaceutical company.

There is a long stream of research that suggests that customer satisfaction with the seller's salespeople have an impact on the customer's loyalty to the firm. For example, Moorman, Zaltman, and Deshpande (1992) in their study of 779 users and providers of market research found that trust and perceived quality of interaction contributed most significantly to research utilization, and in a subsequent study pointed to the interpersonal factors as the most predictive of trust (Moorman, Deshpande, and Zaltman, 1993). Among these factors perceived researcher integrity, willingness to reduce research uncertainty, confidentiality, expertise, tactfulness, sincerity, congeniality, and timeliness were most strongly associated with trust. In a study of advertisers LaBahn (1996) concluded that when advertising agencies behaved cooperatively and attended diligently to the problems that arose, clients were more likely to view them as being compensated fairly, perceived greater rapport in the relationship, and were more likely to show trust in them. In her qualitative study of an advertising agency and its client, Halinen (1997) pointed to the favorable personal relationships with the client's personnel as one of the important factors that increased the bond of attraction between the client and the agency. Broschak (2004) found that the exit of account managers (who in advertising agencies are boundary-spanning personnel) increased the likelihood that the relationship between the client and the service firms would end, but the same did not hold true for creative managers described as the "technical core of advertising agencies" (2004: 629), pointing to the critical role played by boundary-spanners. (For a literature review, please see Athanasopoulou, 2009).

Research on the pharmaceutical company-physician relationship lends support to the importance of the salesperson in this relationship as in other industrial contexts. Some studies (e.g., Beltramini and Sirsi, 1992; Creyer and Hrsistodoulakis, 1998; Spiller and Wymer, 2001) have indicated that physicians find personal sources of information (such as detailers and other physicians) more credible than nonpersonal sources of information (such as advertising). Spiller and Wymer (2001) suggested that physicians' length of service may partly account for their evaluation of pharmaceutical sales representiatives: Their study found that physicians rank pharmaceutical sales representatives highly regardless of the physician's length of service, but that physicians who had been in practice for less than a year gave pharmaceutical sales representatives a higher ranking of usefulness. Creyer and Hrsistodoulakis (1998) found that physicians' impressions of the pharmaceutical industry were formed by their perceptions of the pharmaceutical sales representative's trustworthiness, ethical behavior, and accuracy of information provided, suggesting that a positive perception of the pharmaceutical sales representative leads to a positive perception of the pharmaceutical company he or she represents. Spiller and Wymer (2001) pointed out that physician experience with a given drug, especially a new drug, can often be influenced by the free drug samples distributed by pharmaceutical sales representatives (2001: 102). Finally, Scharitzer and Kollarits (2000) pointed to the service performance of the sales representative as one of the main factors driving competition in the pharmaceuticals market. Specifically, they found a significant 
Journal of Global Strategic Management | V. 12 | N. 2 | 2018-December| isma.info | 037-052 | DOI: 10.20460/JGSM.2019.267 relationship between physicians' satisfaction with the sales representative and their prescription behavior. In view of this body of research and consistent with prior research on customer's satisfaction with the salesperson and commitment to the seller, we propose the following:

Hypothesis 1: Physicians' satisfaction with the pharmaceutical sales representative will significantly determine their commitment to the pharmaceutical company.

Commitment by the customer is an end-goal of relationship marketing efforts (Please see Parvatiyar and Sheth, 2000, for a review of the domain and conceptual foundations of relationship marketing). Commitment has been conceptualized in many studies as the customer's repurchase intention (e.g., Doney and Cannon, 1997). Yet, as important as repurchase or repurchase intention is, one of the moderators of the link between relationship and repurchase has been found to be national culture (e.g., Hewett and Krasnikov, 2016; Samaha, Beck, and Palmatier, 2014; Hewett, Money, and Sharma, 2006). Understanding how relationship marketing operates in different country-markets is critical to the success of relationship marketing efforts. That is why, this study also investigates the differences between foreign and local firms concerning the management of the strategic relationship between the pharmaceutical sales representative and the customer-physician. The differences between the management strategies and styles of foreign and local firms in emerging markets have been well-documented (e.g., Dong, Li, and Tse, 2013; Gülsoy, 2007; Ölmez et al., 2004; Özsomer et al., 1991). It can be assumed that these differences will carry over to the management of the sales force and customer relationships as well as the consequences of those relationships. There is some research, for instance, that points to the differences in sales force training of multinationals vs local companies in Egypt (Attia, Jantan, Atteya, and Fakhr, 2014) and in China and Slovakia (Honeycutt, Ford, Lupton, and Flaherty, 1999).

Hence, it follows that:

Hypothesis 2: The physician's satisfaction with the pharmaceutical sales representative will be significantly different between foreign firms and local firms.

Hypothesis 3: The physician's loyalty to the pharmaceutical firm will be significantly different between foreign firms and local firms.

In the next sections we test the hypotheses developed above and report on our findings and conclusions.

\section{RESEARCH METHOD}

A survey was conducted with physicians from all across Turkey to explore the impact of satisfaction with the pharmaceutical sales representative on the physician's loyalty to the pharmaceutical firm. In Turkey there are around 144,827 physicians, including 78,620 specialists, 43,058 general practitioners, and 23,149 medical residents, according to the most recent Ministry of Health statistics, which date from 2016 (Köse et al., 2017: 205). The sample for this study consisted of 429 specialist physicians. We have confined our investigation to specialist physicians and have excluded general practitioners and medical residents because in Turkey it is only specialist physicians who are authorized to prescribe treatment and related medication (Article 1.10.1 of Social Security Institution's health-related decree dated 2013, with the Official Gazette No. 28597). Another reason for our selection of specialist physicians is that the overwhelming majority $(95.2 \%)$ of prescribed medication in Turkey is medication that is reimbursed to the patient by the government (Pharmaceutical Manufacturers Association of Turkey, 2018: 5), and again for most reimbursable medication, only specialist physician prescriptions are valid. (General practitioners can only repeat-prescribe medication that has already been prescribed by specialist physicians, and nonprescription medication). Our sampling method is described in the next section.

\section{Sampling method}

A three-pronged data collection method was pursued, which is described below. The sampling frame used was the database of Turkey's Social Security Institution (S.G.K.) which contained all of the physicians practicing in those hospitals with which the institution has a contract. (These are state hospitals, private hospitals, or university hospitals. The institution does not include doctors in private practice.) This database (https://gss.sgk.gov.tr/OzelSHSBilgi/pages/shsSorgu.faces) contains the names of 107,359 physicians, including 70,569 specialist physicians, 22,777 general practitioners, and 14,013 medical residents. From this database a list was compiled of 70,569 specialist physicians, including all areas of medical specialty. This list does not contain all of the specialist physicians in Turkey; however, this 
Journal of Global Strategic Management | V. 12 | N. 2 | 2018-December| isma.info | 037-052 | DOI: 10.20460/JGSM.2019.267 number is comparable to the number released by Turkey's Ministry of Health in 2016: 78,620 (Köse et al., 2017: 205).

Initially, in an effort to narrow down the sample to specialist physicians who have the approval authority for reimbursement of medical expenses by the Social Security Institution, a list was compiled from this list of 5,075 physicians with the following specialties: medical oncology, gynaecological oncology surgery, radiation oncology, dermatology, psychiatry, urology, internal medicine, and haematology. All of the 5,075 physicians with the above characteristics were sent an e-mail of the survey questionnaire, and 30 responses were received (response rate $0.59 \%$ ). In an effort to expand the sample the questionnaire was also hand-distributed at the 7th Turkish Medical Oncology Congress held in Antalya, Turkey, between the dates of 21-25 March 2018. We expected that the majority of the participants of the Turkish Medical Oncology Congress would be already included the Social Security Institution database. The data collection at the congress was overseen by the second author of this paper. 65 questionnaires were collected from this medical congress.

Two months later the questionnaire was mailed to 70,179 of the 70,569 specialist physicians included in the Social Security Institution database. The second author of this paper searched for the e-mail addresses of each of these specialist physicians (over a three-week period in October-November 2017), and e-mail addresses were located for 70,179 of the specialist physicians. 427 of those addresses were revealed to be invalid. At the time of writing no response was obtained from this mailing.

The remaining 334 questionnaires were collected at the researcher's discretion from specialist physicians working at a variety of hospitals in Turkey. Thus, the sampling method used was convenience sampling.

\section{The survey instrument}

A 90-item questionnaire was used. The questionnaire consisted of the following parts: Characteristics of the salesperson, characteristics of the salesperson relationship, characteristics of the supplier firm, characteristics of the supplier firm relationship were taken from Doney and Cannon (1997) with the exception of the items pertaining to the following topics: supplier firm willingness to customize for buyer, supplier firm confidential information sharing, purchase choice, anticipated future interaction, delivery performance, relative price/cost. The reason why some sections of the Doney and Cannon (1997) instrument were not included was because of the lack of relevance of those aspects to the physicianpharmaceutical sales representative relationship context. The scales for measuring satisfaction with the salesperson, satisfaction with the pharmaceutical firm, and satisfaction with the pharmaceutical product prescribed from the firm were adapted from Homburg and Rudolph (2001) while the scale used for measuring loyalty was adapted from Zeithaml, Berry and Parasuraman (1996), Bettencourt (1997), Srinivasan, Anderson and Ponnavolu (2002), and Rutherford (2012). Two ratio-scale questions measuring overall satisfaction and overall loyalty as well as questions regarding firm ownership and interaction frequency between the physician and the pharmaceutical sales representative were added by the first author of this paper.

For this study only the 22 Doney and Cannon (1997) items and the 7 Homburg and Rudolph (2001) items were used. The first 22 items above have a 5-point Likert scale where $5=$ Definitely Agree and $1=$ Definitely Disagree while the remaining seven items again had a 5-point scale where $5=$ Very Satisfied and 1=Not Satisfied At All. We also used two items to measure overall satisfaction with the pharmaceutical sales representative and the physician's intention to prescribe medication by the pharmaceutical company that the sales representative represents.

The questionnaire was translated into Turkish by the first author of this paper, and a native speaker of Turkish and a professional teacher of English checked the translation from the English. To ascertain face validity as well as check the translation and the wording, expert opinion was sought from eight physicians now working for the pharmaceutical industry and two pharmaceutical sales representatives, with an average of fifteen years of industry experience (Among the ten experts consulted, the least industry experience was at nine years). They examined an earlier version of the instrument in Turkish and were all interviewed by the second author of this paper for their views on each individual item of the questionnaire. Each interview lasted about half an hour. The interviews were taped, and the transcriptions of the tapes are available. As a result of the insights provided by the interviewees, some of the questions were reworded and some questions were eliminated from the final version of the instrument. 


\section{Data analysis}

In this study the pharmaceutical sales representative's impact on physician's firm loyalty was explored through a linear regression analysis. Both the dependent and independent variables were assumed to distribute normally, based both on residual distribution and on skewness and kurtosis values that were within acceptable ranges, i.e., absolute skew values below 2 and absolute kurtosis values below 7 for sample sizes over 300 (West, Finch and Curran, 1995, as cited in Kim, 2013). We explored whether the physician's satisfaction with the pharmaceutical sales representative differed between the pharmaceutical firm's ownership status (multinational or local) by an independent samples t-test. The physician's loyalty to the pharmaceutical firm was also examined by an independent samples t-test to see if any differences existed between multinational and local firms.

\section{FINDINGS}

In the following sections we first report the descriptives of our study to be followed by the analyses geared towards our hypotheses.

\section{Descriptives}

Of the 429 physicians who have responded to our survey thus far $67.8 \%$ were men, and $32.2 \%$ were women. This group of physicians' mean age was 41.02 (with minimum at 30 and maximum at 68 ), and they had on average 9.43 years of professional experience (with minimum at 1 , and maximum at 27). These 429 specialist physicians included 37 professors (8.6\%) and 58 associate professors (13.5\%). Most frequently represented specialties were medical oncology $(24.0 \%)$, internal medicine $(17 \%)$, urology $(9.3 \%)$, dermatology $(6.3 \%)$, gynecology $(5.1 \%)$, and pediatrics $(5.1 \%)$. Half of the physician respondents worked for state hospitals (50.6\%), 29.6\% were employed by private hospitals, and the remainder $(19.8 \%)$ worked for university hospitals in Turkey. An overwhelming majority of these physicians were working in Istanbul (80.9\%), with Ankara (4.7\%) and Izmir (3.0\%), coming as second and third.

The majority of the pharmaceutical sales representatives these physicians chose to evaluate worked for multinational firms: 321 physicians (74.8\%) evaluated the sales representatives of foreign pharmaceuticals companies while $108(25.2 \%)$ evaluated those of local pharmaceuticals companies. The reason for the heavy tilting towards foreign pharmaceutical company representatives may be explained by the type of products used by specialist physicians: Detailing is most likely to be conducted for new products; and those new products may be produced more by multinational companies with greater access to the significant amount of financial resources required for new product development, as noted for example by Tellis, Prabhu, and Chandy (2009) and Story, Boso, and Cadogan (2015). It is also worth noting that of the world's top research and development spenders, pharmaceutical companies such as Roche, Novartis, Johnson \& Johnson, and Merck figure in the top ten (Casey and Hackett, 2014). The hospitals where the physicians participating in our survey have been working were being called on by these sales representatives on average for 2.56 years, and the duration of the relationship of the physician's hospital with the relevant pharmaceutical firm was on average 8.71 years.

\section{Dimensions of the physician's satisfaction with the pharmaceutical sales representative}

The physician's satisfaction with the pharmaceutical sales representative was measured by 29 items (Doney and Cannon, 1997; Homburg and Rudolph, 2001). The descriptives of these items are reported in Table 1. Physicians appear to be most satisfied with the sales representative's friendliness and gave the lowest score to the representative's personnel continuity. 
Journal of Global Strategic Management | V. 12 | N. 2 | 2018-December| isma.info | 037-052| DOI: 10.20460/JGSM.2019.267

Table 1: Physicians' evaluations of pharmaceutical sales representatives' characteristics

\begin{tabular}{|c|c|c|c|}
\hline & $\mathrm{N}$ & Mean & $\begin{array}{c}\text { Std. } \\
\text { Deviation }\end{array}$ \\
\hline This pharmaceutical sales representative is friendly. & 429 & 4,72 & ,492 \\
\hline Satisfaction with the pharmaceutical sales representative's friendliness & 429 & 4,72 & ,487 \\
\hline This pharmaceutical sales representative is not trustworthy. (R) & 429 & 4,69 & ,509 \\
\hline Satisfaction with the pharmaceutical sales representative's visiting frequency & 429 & 4,67 &, 585 \\
\hline This pharmaceutical sales representative is always nice to us. & 429 & 4,65 &, 514 \\
\hline This pharmaceutical sales representative frequently visits our place of business. & 429 & 4,65 &, 579 \\
\hline The people at my firm do not trust this pharmaceutical sales representative. (R) & 429 & 4,62 &, 519 \\
\hline This pharmaceutical sales representative has been frank in dealing with us. & 429 & 4,62 &, 546 \\
\hline This pharmaceutical sales representative does not seem to be concerned with our needs. (R) & 429 & 4,52 & ,582 \\
\hline $\begin{array}{l}\text { Satisfaction with the time taken by the pharmaceutical sales representative in reacting to } \\
\text { physician's requests for visits }\end{array}$ & 429 & 4,49 & ,625 \\
\hline This pharmaceutical sales representative does not make false claims. & 429 & 4,48 & ,665 \\
\hline $\begin{array}{l}\text { We do not think this pharmaceutical sales representative is completely open in dealing with us. } \\
\text { (R) }\end{array}$ & 429 & 4,32 &, 549 \\
\hline This pharmaceutical sales representative is not an expert. (R) & 429 & 4,29 & ,646 \\
\hline This pharmaceutical sales representative is only concerned about himself/herself. (R) & 429 & 4,28 & ,605 \\
\hline This pharmaceutical sales representative takes a lot of time learning our needs. & 429 & 4,20 & ,592 \\
\hline Satisfaction with the product knowledge of the pharmaceutical sales representative & 429 & 4,17 & ,690 \\
\hline This pharmaceutical sales representative knows his/her product line very well. & 429 & 4,11 & ,658 \\
\hline $\begin{array}{l}\text { Satisfaction with the support in problem solving provided by this pharmaceutical sales } \\
\text { representative }\end{array}$ & 429 & 4,04 & ,873 \\
\hline $\begin{array}{l}\text { Satisfaction with the pharmaceutical sales representative's knowledge regarding the usage } \\
\text { conditions for the medication he/she represents }\end{array}$ & 429 & 3,99 &, 576 \\
\hline This pharmaceutical sales representative is very knowledgeable. & 429 & 3,86 & ,612 \\
\hline This pharmaceutical sales representative is someone we like to have around. & 429 & 3,85 & ,636 \\
\hline $\begin{array}{l}\text { This pharmaceutical sales representative is one of the most important salespeople of the } \\
\text { pharmaceutical company for which he/she works. }\end{array}$ & 429 & 3,76 & ,747 \\
\hline This pharmaceutical sales representative has power in his/her firm. & 429 & 3,73 & ,802 \\
\hline This pharmaceutical sales representative has the clout to get his/her way with his/her company. & 429 & 3,71 & ,712 \\
\hline This salesperson shares similar interests with people in our firm. & 429 & 3,44 & 644 \\
\hline This salesperson spends considerable time getting to know other physicians in our firm. & 429 & 3,39 & ,703 \\
\hline This salesperson has values similar to people in our firm. & 429 & 3,34 & 657 \\
\hline This salesperson is very similar to people in our firm. & 429 & 3,29 & ,707 \\
\hline Satisfaction with the personnel continuity of the pharmaceutical sales representative & 429 & 3,18 & ,863 \\
\hline Valid N (listwise) & 429 & & \\
\hline
\end{tabular}

\section{The relationship between satisfaction with the sales representative and customer loyalty}

A bivariate linear regression analysis was conducted to find the underlying relationship between overall satisfaction with the pharmaceutical sales representative and the physician's overall loyalty to the pharmaceutical company (as measured by intention to continue to prescribe the products of the pharmaceutical company). A strong positive relationship was found between satisfaction with the pharmaceutical sales representative and intention to continue prescribing the medication of the pharmaceutical firm: $\mathrm{F}(1,427)=2,403.30, \rho<0.01$, with $\mathrm{R}^{2}=0.849$. The beta value of the independent variable of physician's satisfaction with the representative was $0.92(\mathrm{t}=49.02, \rho<0.01)$. Thus, preliminary findings indicate a strong positive relationship between satisfaction with the pharmaceutical 
Journal of Global Strategic Management | V. 12 | N. 2 | 2018-December| isma.info | 037-052 | DOI: 10.20460/JGSM.2019.267 sales representative and physician's loyalty. Our first hypothesis that satisfaction with the pharmaceutical sales representative will significantly determine loyalty to the pharmaceutical company received support.

\section{The physician's satisfaction with the pharmaceutical sales representative: Foreign vs local pharmaceutical firms}

Preliminary findings indicate a significant difference in the physician's overall satisfaction with pharmaceutical sales representatives based on whether the sales representative's firm is foreign or local. Physicians working with the sales representatives of multinational firms appear to be happier with their sales representatives on average on a ratio scale of 0 to 100 (mean=81.65; S.D.= 7.83) while for physicians working with the sales representatives of local firms, satisfaction with the sales representative is barely 63.75 (S.D. = 9.74). An independent t-test analysis has revealed a significant difference at $\rho<.01$ $(\mathrm{t}=17.31 ; \mathrm{df}=156.14)$. As a result of this analysis, our Hypothesis 2 was supported.

The specific areas where the differences were most pronounced $(\rho<0.01)$ are the representative's product knowledge, problem-solving capability, product line knowledge, knowledge of product usage conditions, knowledgeability, and having importance and power in his or her company. In all of these aspects the representatives of foreign companies fared better than those of local companies. The areas where local pharmaceutical company representatives were evaluated higher than their counterparts in foreign companies were the attributes of being similar to and having similar values and interests with the people in the physician's firm $(\rho<0.10)$. (Note: All t-tests are two-tailed.) We also conducted the nonparametric analysis of the Mann-Whitney $\mathrm{U}$ test and found similar results.

\section{The physician's loyalty to the firm: Foreign vs local pharmaceutical firms}

As reported above, the physician's loyalty to the firm was measured by several items; however, in the analyses for this study only one item is taken into consideration: the physician's intention to continue to prescribe medication by the pharmaceutical firm, on a ratio scale of 0 to 100 . Preliminary findings indicate that there is a significant difference in the physician's intention to prescribe medication by the pharmaceutical firm based on whether the pharmaceutical firm is multinational or local. Physicians working with the sales representatives of multinational firms report a greater intention of continuing to prescribe medication by the pharmaceutical firm when that firm is multinational (Mean $=75.56$; S.D. $=$ 7.83 ) versus when it is local (Mean $=56.62 ;$ S.D. $=9.37)$. An independent t-test analysis has revealed a significant difference at $\rho<0.01(\mathrm{t}=18.98 ; \mathrm{df}=158.08)$. Hence, our Hypothesis 3 was also supported. Please see Table 2 for a summary of the analyses conducted to test for Hypotheses 2-3. We also conducted the nonparametric analysis of the Mann-Whitney $U$ test and found similar results. These findings have some important implications for managers.

Table 2: Relationship Outcomes of Physician and Pharmaceutical Sales Representative: Foreign vs Local Pharmaceutical Companies

\begin{tabular}{|l|l|l|l|}
\hline & Foreign & Local & $\mathrm{T}$ \\
\hline $\mathrm{N}$ & 321 & 108 & \\
\hline $\begin{array}{l}\text { Satisfaction with Pharmaceutical Sales } \\
\text { Representative }\end{array}$ & 81.65 & 63.75 & $17.31^{* *}$ \\
\hline Standard deviation & 7.83 & 9.74 & \\
\hline & & & \\
\hline Loyalty to Company & 75.56 & 56.62 & $18.98 * *$ \\
\hline Standard deviation & 7.68 & 9.37 & \\
\hline$* * p<0.01$ & & & \\
\hline Note: All t-tests are two-tailed. & & & \\
\hline
\end{tabular}




\section{CONCLUSION AND DISCUSSIONS}

Our findings point to some significant differences between local and foreign pharmaceutical companies in the perceptions of physician customers. Pharmaceutical sales representatives of multinationals appear to fare better in overall satisfaction as well as in terms of specific attributes such as expertise and power. Furthermore, physicians report greater intention to continue their prescription behavior concerning multinational firms than local firms.

\section{Managerial implications}

This study has several implications for managers of business-to-business marketing in the emergingmarket context. For one, the indication that the physician's overall satisfaction with the pharmaceutical sales representatives of foreign firms is significantly greater than that for local firms should send a sign of warning to local pharmaceutical companies. Examination of the individual attributes of salesperson evaluation points to some interesting implications. One of the most significant differences emerges in knowledgeability and product knowledge, on which sales representatives of foreign pharmaceutical companies fared better. This finding suggests that local companies should increase training opportunities for their pharmaceutical sales representatives. Another difference emerged in the power accorded to the salesperson, which suggests that multinational companies allow their pharmaceutical sales representatives greater initiative and leeway in solving customer problems and meeting customer requirements. An implication that suggests itself for local companies is increasing the initiative allowed pharmaceutical sales representatives. An interesting finding is that on likeability aspects such as similarity to the people in the physician's company and having similar interests and values with them, sales representatives of local pharmaceutical companies fared better, but this did not seem to translate into greater satisfaction on the part of the physician. To establish this point, however, more fine-grained analyses need to be made. Nonetheless, based on this finding it seems as though physicians seem to lay greater store by expertise than by likeability.

The findings also suggest a strong positive relationship between satisfaction with the pharmaceutical sales representative and positive prescription behavior, pointing to the importance of the salesperson in the relationship between the physician and the pharmaceutical company.

\section{Limitations of the study and implications for future research}

This study has several limitations. For one, the sampling method used is convenience sampling, and therefore, the generalizability of the results is limited. Not all of the medical specialties are represented in our sample of physicians, and that constitutes another limitation of the study. A third limitation is the cross-sectional design. Longitudinal designs may capture the dynamics of satisfaction with the salesperson and customer loyalty more accurately. Fourthly, the sample is tilted towards physicians evaluating the sales representatives of foreign pharmaceutical companies; while the rationale for this was explained in our findings section, it does nonetheless constitute a bias, and future studies with a more balanced representation may yield a more accurate picture of the physician's satisfaction dimensions with pharmaceutical sales representatives. Furthermore, in this preliminary study only the construct of satisfaction with the salesperson was used as a determinant of customer loyalty; satisfaction with the product and satisfaction with the pharmaceutical company were not taken into consideration. When those variables are taken into consideration, a more realistic picture of the relationship between the physician and the pharmaceutical company would emerge. Finally, this study relies on self-reports of intended prescription behavior and hence is subject to same-source bias; future studies could use more objective measures of actual prescription behavior. 


\section{Acknowledgments}

We thank the editor of the Journal of Global Strategic Management, Professor Cemal Zehir, for his constructive comments. We owe special thanks to the eight physicians and the two pharmaceutical sales representatives who were interviewed by the second author of this study for their prescient views that have guided the development of the survey questionnaire.

\section{Note}

An earlier version of this paper was presented at the 14th International Strategic Management Conference, organized by the International Strategic Management and Managers Association of Istanbul, Turkey, in collaboration with Istanbul Technical University, Gebze Technical University, Yıldiz Technical University, University of Economics Prague, and the University of Bari Aldo Moro, on 12-14 July 2018, in Prague, Czech Republic. This paper is based on the data collected as part of the research carried out for the doctoral dissertation of the second author. 


\section{REFERENCES}

Athanasopoulou, Pinelopi. (2009). "Relationship quality: A critical research review and research agenda." European Journal of Marketing, 43 (5/6): 583-610.

Attia, Ashraf M.; Jantan, M. Asri; Atteya, Nermine; and Fakhr, Rana. (2014). Sales training: Comparing multinational and domestic companies. Marketing Intelligence and Planning, 32 (4): 124-138.

Beltramini, Richard F.; and Sirsi, Ajay K. (1992). Physician information acquisition and believability: A field experiment on source and type of information. Journal of Health Care Marketing, 12 (4): 52-58.

Bettencourt, Lance A. (1997). "Customer voluntary performance: Customers as partners in service delivery." Journal of Retailing, 73 (3): 383-406.

Broschak, Joseph P. (2004). "Manager's mobility and market interface: The effect of managers' career mobility on the dissolution of market ties.” Administrative Science Quarterly, 49: 608-640.

Burton, Patrick. (2018). Top 15 pharma companies in Turkey ranking. Pharmaboardroom. Retrieved in September 2018 from https://pharmaboardroom.com/facts/top-15-pharma-companies-in-turkey-ranking.

Buttle, Francis. (1996). "What is relationship marketing?" In Francis Buttle (Ed.), Relationship Markeiing: Theory and Practice (pp. 1-16). London, UK.: Paul Chapman Publishing Ltd.

Casey, Michael and Hackett, Robert. (2014, November 17). "Ten biggest R\&D spenders worldwide." Fortune. Retrieved in May 2018 from http://fortune.com/2014/11/17/top-10-research-development/.

Cheng, Jessie. (2008). "An antitrust analysis of product hopping in the pharmaceutical industry." Columbia Law Review, 108: 1471-1515.

Civaner, Murat. (2012). "Sale strategies of pharmaceutical companies in a 'pharmerging' country: The problems will not improve if the gaps remain." Health Policy, 106: 225-232.

Creyer, Elizabeth H.; and Hrsistodoulakis, Ilias. (1998). Marketing pharmaceutical products to physicians: Sales reps influence physicians' impressions of the industry. Marketing Health Services, 18 (2): 34-38.

Crosby, Lawrence A.; Evans, Kenneth R., and Cowles, Deborah. (1990). "Relationship quality in services selling: An interpersonal influence perspective." Journal of Marketing, 54 (July): 68-81.

Doney, Patricia M. and Cannon, Joseph P. (1997). "An examination of the nature of trust in buyer-seller relationships." Journal of Marketing, 61 (April): 35-51.

Dong, Maggie Chuoyan; Li, Caroline Bingxin; and Tse, David K. (2013). "Do business and political ties differ in cultivating marketing channels for foreign and local firms in China?" Journal of International Marketing, 21 (1): 39-56.

Dwyer, F. Robert; Schurr, Paul H., and Oh, Sejo. (1987). "Developing buyer-seller relationships." Journal of Marketing, 51 (April): 11-27.

Fickweiler, Freek; Fickweiler, Ward; and Urbach, Ewout. (2017). Interactions between physicians and the pharmaceutical industry generally and sales representatives specifically and their association with physicians' attitudes and prescribing habits: A systematic review. BMJ Open, 7: 1-12.

Gorokhovich, L.E.; Chalkidou, K.; and Shankar, R. (2013). Improving access to innovative medicines in emerging markets: Evidence and diplomacy as alternatives to the unsustainable status quo. Journal of Health Diplomacy, 1 (1): 1-19.

Gummesson, Evert. (2002). Total Relationship Marketing: Marketing Management, Relationship Strategy and CRM Approaches for the Network Economy. Oxford, UK: Butterworth-Heinemann.

Gülsoy, Tanses. (2007). "Do MNCs and local companies differ in their relationship with ad agencies?" Dokuz Eylül University Journal of Faculty of Business, 8 (1): 87-102.

Halinen, Aino. (1997). Relationship Marketing in Professional Services: A Study of Agency-Client Dynamics in the Advertising Sector. London, UK: Routledge. 
Journal of Global Strategic Management | V. 12 | N. 2 | 2018-December| isma.info | 037-052 | DOI: 10.20460/JGSM.2019.267

Hewett, Kelly; Money, R. Bruce; and Sharma, Subash. (2006). National culture and industrial buyerseller relationships in the United States and Latin America. Academy of Marketing Science Journal, 34 (3): 386-402.

Hewett, Kelly, and Krasnikov, Alexander V. (2016). "Investing in buyer-seller relationships in transitional markets: A market-based assets perspective." Journal of International Marketing, 24 (1): 5781.

Homburg, Christian and Rudolph, Bettina. (2001). "Customer satisfaction in industrial markets: Dimensional and multiple role issues.” Journal of Business Research, 52: 15-33.

Honeycutt, Earl D., Jr.; Ford, John B.; Lupton, Robert A., and Flaherty, Theresa B. (1999). Selecting and training the international sales force: Comparison of China and Slovakia. Industrial Marketing Management, 28: 627-635.

Huang, Ying; Luo, Yadong; Liu, Yi; and Yang, Qian. (2013). An investigation of interpersonal ties in interorganizational exchanges in emerging markets: A boundary-spanning perspective. Journal of Management, 42 (6): 1557-1587.

Khanna, Tarun, and Palepu, Krishna. (1997). Why focused strategies may be wrong for emerging markets. Harvard Business Review, 75 (4/July-August): 41-51.

Kim, Hae-Young. (2013). Statistical notes for clinical researchers: assessing normal distribution (2) using skewness and kurtosis. Restorative Dentisty and Endodontics, 2013: 52-54. The Korean Academy of Conservative Dentistry. Retrieved in September 2018, from https://synapse.koreamed.org/Synapse/Data/PDFData/2185RDE/rde-38-52.pdf.

Kotler, Philip, and Keller, Kevin Lane. (2016). Marketing Management, $15^{\text {th }}$ edition. Essex, UK: Pearson Education Ltd.

Köse, Mehmet Rifat; Başara, Berrak Bora; Güler, Cemil; Çă̆lar, İrem Soytutan; Özdemir, Tuğcan Adem; Aygün, Asiye; Uzun, Selen Begüm; Yentür, Gökalp Kadri; Pekeriçli, Ayfer; Kayış, Birsen Birge; and Kılıç, Dilek Aydoğan. (2017). Ministry of Health Health Statistics Yearbook 2016. Ankara: Ministry of Health. Retrieved in September 2018 from https://dosyasb.saglik.gov.tr/Eklenti/13160,sy2016enpdf.pdf?0.

LaBahn, Douglas W. (1996). Advertiser perceptions of fair compensation, confidentiality, and rapport. Journal of Advertising Research, (March/April): 28-38.

Manchanda, Puneet; Xie, Ying; and Youn, Nara. (2008). The role of targeted communication and contagion in product adoption. Marketing Science, 27 (6): 961-976.

Moorman, Christine; Zaltman, Gerald; and Deshpande, Rohit. (1992). Relationships between providers and users and market research: The dynamics of trust within and between organizations. Journal of Marketing Research, 29 (August): 314-328.

Moorman, Christine; Deshpande, Rohit; and Zaltman, Gerald. (1993). Factors affecting trust in market research relationships. Journal of Marketing, 57 (January): 81-101.

Morgan, Robert M. (2000). "Relationship marketing and marketing strategy: The evolution of relationship marketing strategy within the organization.” In Jagdish N. Sheth and Atul Parvatiyar (Eds.), Handbook of Relationship Marketing (pp. 481-504). Thousand Oaks, California: Sage Publications Inc.

Ölmez, A.E.; Sümer, H.C., and Soysal, M. (2004). “Organizational rationality in public, private and multinational firms in Turkey. Information Knowledge Systems Management, 4: 107-118.

Özsomer, Ayşegül; Bodur, Muzaffer, and Çavuşgil, S. Tamer. (1991). "Marketing standardisation by multinationals in an emerging market.” European Journal of Marketing, 25 (12): 50-64.

Palmatier, Robert W.; Dant, Rajiv P.; Grewal, Dhruv; and Evans, Kenneth R. (2006). Factors influencing the effectiveness of relationship marketing: A meta-analysis. Journal of Marketing, 70 (October): 136-153.

Palmatier, Robert W.; Scheer, Lisa K.; and Steenkamp, Jan-Benedict E.M.. (2007). Customer loyalty to whom? Managing the benefits and risks of salesperson-owned loyalty. Journal of Marketing Research, 44 (2): 185-199. 
Journal of Global Strategic Management | V. 12 | N. 2 | 2018-December| isma.info | 037-052 | DOI: 10.20460/JGSM.2019.267 Parvatiyar, Atul \& Sheth, Jagdish N. (2000). "The domain and conceptual foundations of relationship marketing." In Jagdish N. Sheth and Atul Parvatiyar (Eds.), Handbook of Relationship Marketing (pp. 338). Thousand Oaks, California: Sage Publications Inc.

Pharmaceutical Manufacturers Association of Turkey (IEIS). (2018). Turkish Pharmaceutical Market 2017. Istanbul: Pharmaceutical Manufacturers Association of Turkey (İlaç Endüstrisi İşverenler Sendikas1). Retrieved in September 2018 from http://ieis.org.tr/ieis/en/sektorraporu2017/.

Rutherford, Brian. (2012). "Building buyer commitment to the salesperson." Journal of Business Research, 65: 960-967.

Samaha, Stephen A.; Beck, Joshua T.; and Palmatier, Robert W. (2014). The role of culture in international relationship marketing. Journal of Marketing, 78 (September): 78-98.

Scharitzer, Dieter, and Kollarits, Haralde. (2000). "Satisfied customers: Profitable customer relationships: Pharmaceutical marketing: How pharmaceutical sales representatives achieve economic success through relationship management with settled general practitioners: An empirical study." Total Quality Management, 11 (7): S955-S965.

Seabright, Mark A.; Levinthal, Daniel A.; and Fichman, Mark. (1992). "Role of individual attachments in the dissolution of interorganizational relationships." Academy of Management Journal, 35 (1): $122-$ 160 .

Spiller, Lisa D.; and Wymer, Walter W. Jr. (2001). Physicians' perceptions and uses of commercial drug information sources: An examination of pharmaceutical marketing to physicians. Health Marketing Quarterly, 19 (1): 97-106.

Srinivasan, Srini S.; Anderson, Rolph, and Ponnavolu, Kishore. (2002). "Customer loyalty in ecommerce: An exploration of its antecedents and consequences.” Journal of Retailing, 78: 41-50.

Statista. (2018a). "Total global pharmaceutical research and development (R\&D) spending from 2008 to 2022 (in billion U.S. dollars)." Retrieved on June 7, 2018, from https://www.statista.com/statistics/309466/global-r-and-d-expenditure-for-pharmaceuticals/.

Statista. (2018b). "Top ten global pharmaceutical and biotech companies based on total revenue 2017 (in million US dollars)." Retrieved on June 7, 2018, from https://www.statista.com/statistics/272717/top-globalbiotech-and-pharmaceutical-companies-based-on-revenuel.

Story, Vicky M.; Boso, Nathaniel; Cadogan, John W. (2015). The form of relationship between firm-level product

innovativeness and new product performance in developed and emerging markets. Journal of Product Innovation Management, 32 (1): 45-64.

Tengilimoglu, Dilaver; Kisa, Adnan; and Ekiyor, Aykut. (2004). The pharmaceutical sales rep/physician relationship in Turkey: Ethical issues in an international context. Health Marketing Quarterly, 22 (1): 21 39.

Tannoury, Maya; and Attieh, Zouhair. (2017). The influence of emerging markets on the pharmaceutical industry. Current Therapeutic Research, 86: 19-22.

Tellis, Gerard J.; Prabhu, Jaideep C.; and Chandy, Rajeesh K. (2009). Radical innovation across nations: The preeminence of corporate culture. Journal of Marketing, 73 (January): 3-23.

Turnbull, Peter; Ford, David; and Cunningham, Malcolm. (2002). "Interaction, Relationships and Networks in Business Markets: An Evolving Perspective.” In David Ford (Ed.), Understanding Business Marketing and Purchasing, pp. 3-18. London, UK: Thomson Learning.

Waheed, Kareem Abdul; Jaleel, Mohammad; and Laeequddin, Mohammed. (2011). "Prescription loyalty behavior of physicians: An empirical study in India." International Journal of Pharmaceutical and Healthcare Marketing, 5 (4): 279-298.

Williams, James R. and Hensel, Paul J. (1991). Changes in physicians' sources of pharmaceutical information: A review and analysis. Journal of Health Care Marketing, 11 (3): 46-60. 
Journal of Global Strategic Management | V. 12 | N. 2 | 2018-December| isma.info | 037-052 | DOI: 10.20460/JGSM.2019.267 World Bank, The. (2018). "Population.” Washington, D.C.: The World Bank. Retrieved on June 6, 2018, from the organization's official Web site https://data.worldbank.org/country/turkey.

Wright, Robert F. and Lundstrom, William J. (2004). Physicians' perceptions of pharmaceutical sales representatives: A model for analysing the customer relationship. International Journal of Medical Marketing, 4 (1): 29-38.

Zeithaml, Valarie A.; Berry, Leonard L., and Parasuraman, A. (1996). "The behavioral consequences of service quality." Journal of Marketing, 60 (April): 31-46. 